Case Report

\title{
Spontaneous Accumulation of Globotriaosylceramide (Gb3) in Proximal Renal Tubules in an ICR Mouse
}

\author{
Mayu Mutsuga ${ }^{1}$, Yoshiji Asaoka ${ }^{1}$, Yuko Togashi ${ }^{1}$, Naoko Imura ${ }^{1}$, Tomoya Miyoshi ${ }^{1}$, \\ and Yohei Miyamoto ${ }^{1 *}$ \\ ${ }^{1}$ Toxicology and Pharmacokinetics Laboratories, Pharmaceutical Research Laboratories, Toray Industries, Inc., 6-10-1 Tebiro, \\ Kamakura, Kanagawa 248-8555, Japan
}

\begin{abstract}
This report describes spontaneous cytoplasmic vacuolation in the proximal renal tubules of a 7-week-old male ICR [Crlj:CD1(ICR)] mouse. The contents of vacuoles were positively stained with periodic acid-Schiff (PAS) and Sudan black, and the membranes were positive on immunohistochemical staining for lysosomal-associated membrane protein-2 (LAMP-2), a marker of lysosomal membrane. Electron microscopy revealed electron-dense lamellar bodies in the proximal tubular epithelial cells. These histopathological features are similar to those in $\alpha$-galactosidase A-deficient mice, in which globotriaosylceramide (Gb3), a glycosphingolipid, accumulates in lysosomes. When we performed immunohistochemical staining for $\mathrm{Gb} 3$, the contents of vacuoles were positively stained. From these results, spontaneous cytoplasmic vacuolation in the proximal renal tubules in the mouse was identified as lysosomal accumulation of Gb3. (DOI: 10.1293/tox.2013-0029; J Toxicol Pathol 2013; 26: 429-432)
\end{abstract}

Key words: globotriaosylceramide (Gb3), mouse, proximal renal tubules, spontaneous cytoplasmic vacuolation

It is well known that many chemicals induce cytoplasmic vacuolation in renal tubular epithelial cells, which might be an early sign of irreversible necrosis or represent a reversible change ${ }^{1}$. In addition, certain drugs could induce lysosomal accumulation of phospholipids, phospholipidosis, and this is microscopically observed as vacuoles ${ }^{2,3}$. Furthermore, vacuolation in renal tubules occurs spontaneously with various incidences in some experimental animals, but little is known about their pathogenesis ${ }^{4-13}$. In this study, we observed the histopathological details of spontaneous cytoplasmic vacuolation in proximal renal tubules in a male mouse.

The animal was a 7-week-old male ICR mouse [Crlj:CD1(ICR); Charles River Laboratories Japan, Inc., Yokohama, Japan] orally administered a vehicle, $0.5 \%$ methyl cellulose solution containing $0.4 \%$ Tween 80 , for 5 days in a toxicity study. The mouse was housed in a plastic cage with softwood chip bedding under controlled conditions (12 h light/dark cycle, $40-60 \%$ humidity at $\left.19-25^{\circ} \mathrm{C}\right)$ and fed a standard diet (CRF-1; Oriental Yeast Co., Ltd., Tokyo, Japan) and tap water ad libitum. The animal experiments were conducted according to the Guidelines for Animal

Received: 30 May 2013, Accepted: 16 July 2013

*Corresponding author: Y Miyamoto (e-mail: Youhei_Miyamoto@ nts.toray.co.jp)

(C)2013 The Japanese Society of Toxicologic Pathology

This is an open-access article distributed under the terms of the Creative Commons Attribution Non-Commercial No Derivatives (by-ncnd) License $<$ http://creativecommons.org/licenses/by-nc-nd/3.0/> .
Experiments, Research \& Development Division, Toray Industries Inc. The animal showed no marked changes in clinical signs, body weight and the results of hematology, blood chemistry and necropsy, but the weight of the kidneys was 1.3 -fold that in our background data. The kidneys were fixed in 10\% neutral-buffered formalin. Subsequently, hematoxylin and eosin (HE) staining of paraffin sections, periodic acid-Schiff (PAS) staining of frozen sections and Sudan black staining of osmium tetroxide-fixed paraffin sections were performed in the usual manner, respectively. Immunohistochemical staining for lysosomal-associated membrane protein-2 (LAMP-2) of formalin-fixed paraffin sections was performed with a rat monoclonal IgG antibody against mouse LAMP-2 (Santa Cruz Biotechnology, Inc., Santa Cruz, CA, USA) and a HRP-labeled polymerconjugated secondary antibody (Nichirei Biosciences Inc., Tokyo, Japan) ${ }^{3}$. Immunohistochemical staining of formalinfixed frozen sections for globotriaosylceramide (Gb3) was performed with a rat monoclonal IgM antibody against Gb3/ CD77 (Beckman Coulter Inc., Brea, CA, USA) and an Alexa Fluor 488-conjugated secondary antibody (Life Technologies, Carlsbad, CA, USA) $)^{14}$, and tissue preparations were examined under a confocal laser scanning microscope (Olympus IX70, Olympus, Tokyo, Japan) to detect Alexa Fluor 488 (excitation filter, BP 470-490 nm; absorption filter, BA 510-550 nm). For electron microscopy, formalin-fixed kidneys were refixed in $2.5 \%$ glutaraldehyde, postfixed in $1 \%$ osmium tetroxide, and embedded in epoxy resin. Then, ultrathin sections were double-stained with $2 \%$ uranyl acetate and lead citrate, and examined under a transmission 


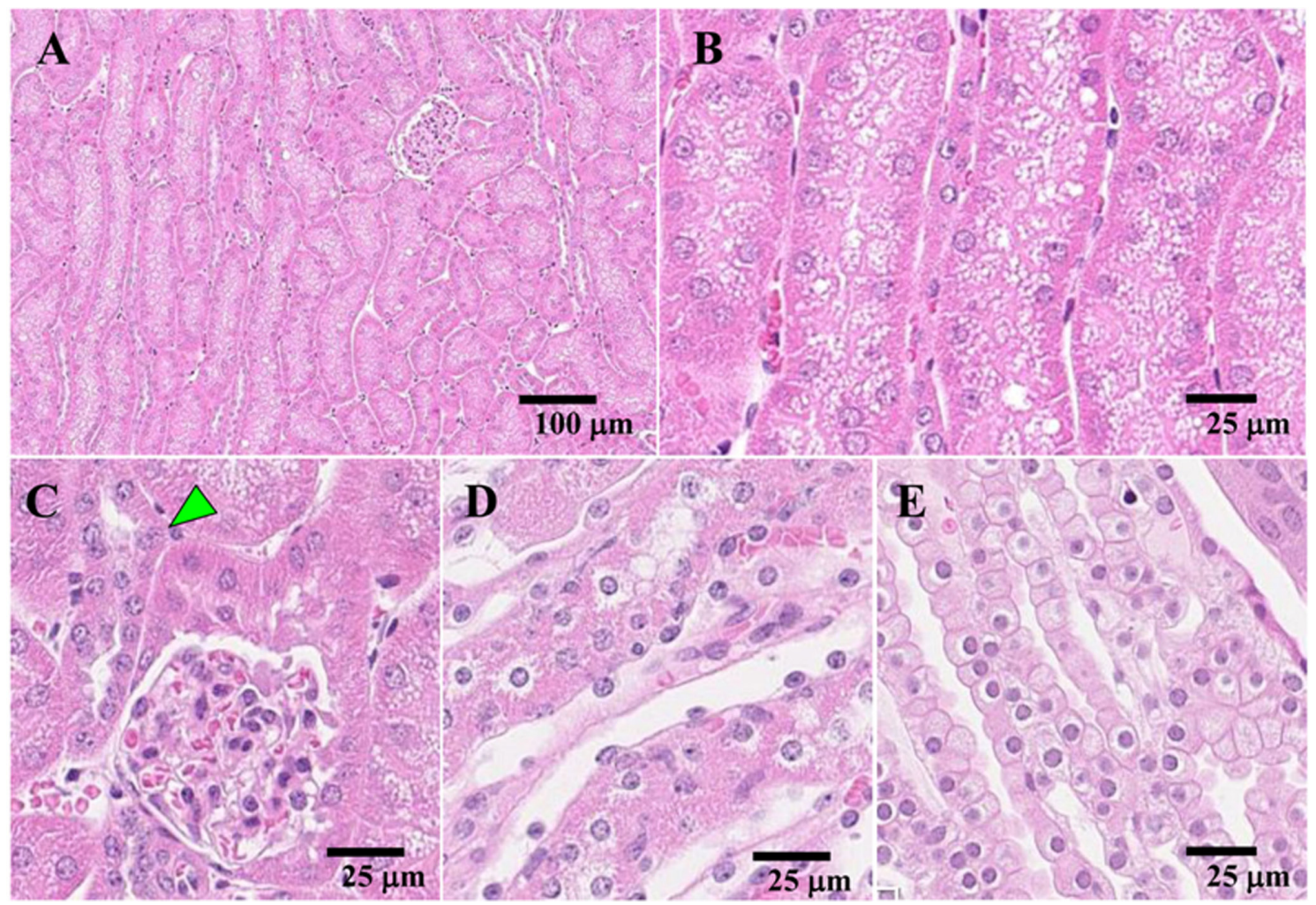

Fig. 1. HE staining in the kidney. Many small clear vacuoles are seen in the apical cytoplasm of the proximal renal tubules (B), but not in the distal renal tubules (C, arrowhead), Henle's loop (D), collecting ducts (E) and glomerulus (C). A, B, C: cortex. D: outer medulla. E: inner medulla.

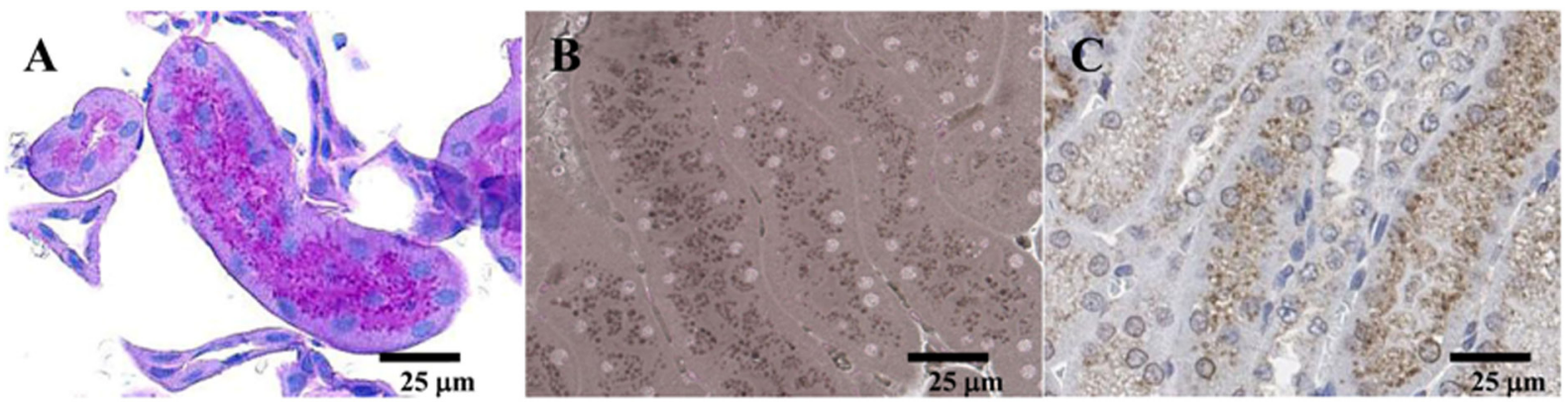

Fig. 2. PAS staining, Sudan black staining, and immunohistochemical staining for LAMP-2 in the proximal renal tubules. The contents of vacuoles are positive for PAS and Sudan black staining (A, B), and the membranes are positive for LAMP-2 immunohistochemical staining (C). A: PAS staining. B: Sudan black staining. C: immunohistochemical staining for LAMP-2.

electron microscope (H7000; Hitachi High-Technologies Corporation, Tokyo, Japan).

Many small clear vacuoles were observed in the apical cytoplasm of proximal renal tubules in the mouse under a light microscope, but not in the distal renal tubules, Henle's loop, collecting ducts and glomerulus (Fig. 1). The contents of vacuoles showed positive PAS and Sudan black staining (Fig. 2A, 2B), and the membranes showed positive immunohistochemical staining for LAMP-2, a marker of the lysosomal membrane (Fig. 2C), indicating the lysosomal accumulation of glycolipids. Electron microscopy revealed electron-dense lamellar bodies in the proximal tubular epithelial cells (Fig. 3). These histopathological features are similar to those in $\alpha$-galactosidase A ( $\alpha$-Gal A)-deficient mice, known as the Fabry disease model, in which $\mathrm{Gb} 3$, a glycosphingolipid, accumulates in lysosomes ${ }^{15,16}$. On immunohistochemical staining for $\mathrm{Gb} 3$, the content of vacuoles showed a positive reaction (Fig. 4). In other organs in this mouse, immunohistochemical staining for $\mathrm{Gb} 3$ was not conducted, since no remarkable change such as vacuolation was observed. From these results, the spontaneous cytoplasmic vacuolation in proximal tubular epithelial cells 


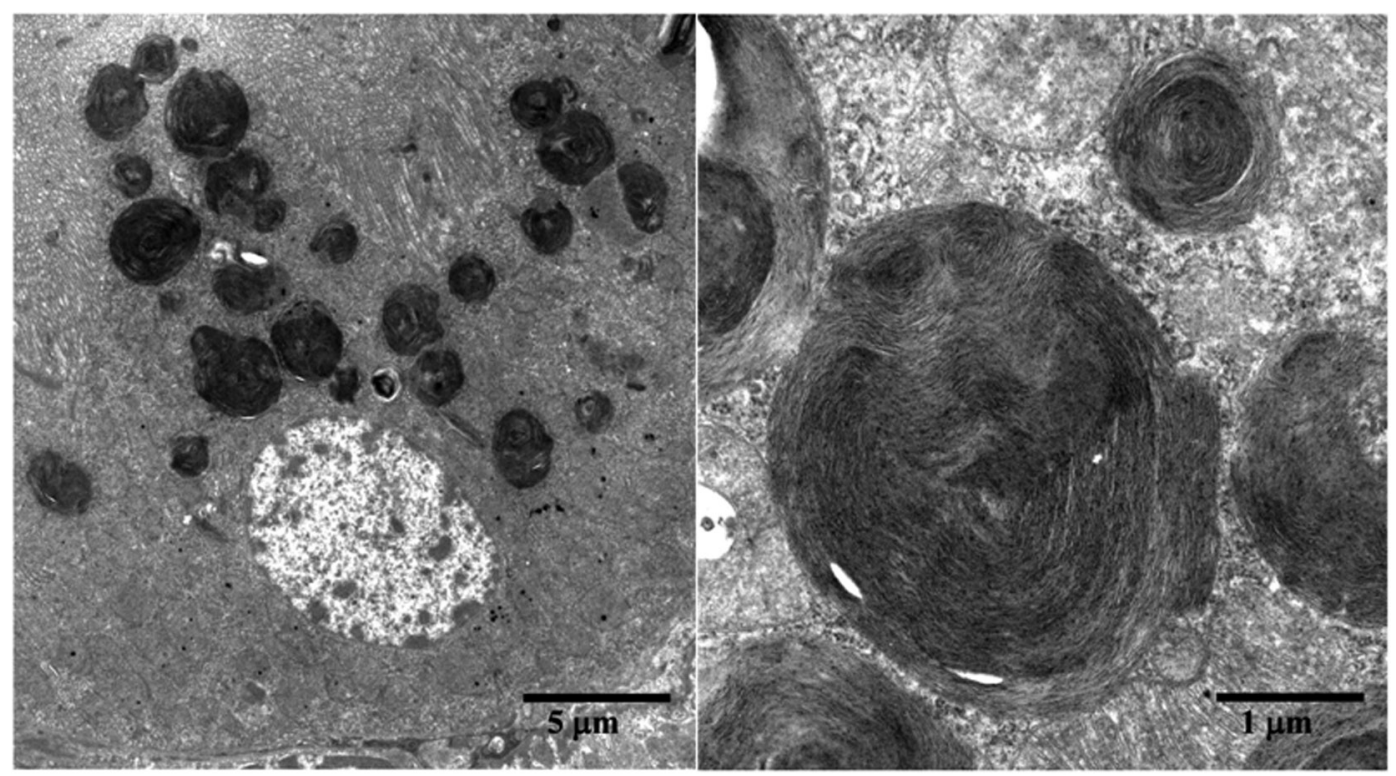

Fig. 3. Electron microscopy in the proximal renal tubules. Electron-dense lamellar bodies are seen in the proximal tubular epithelial cells.

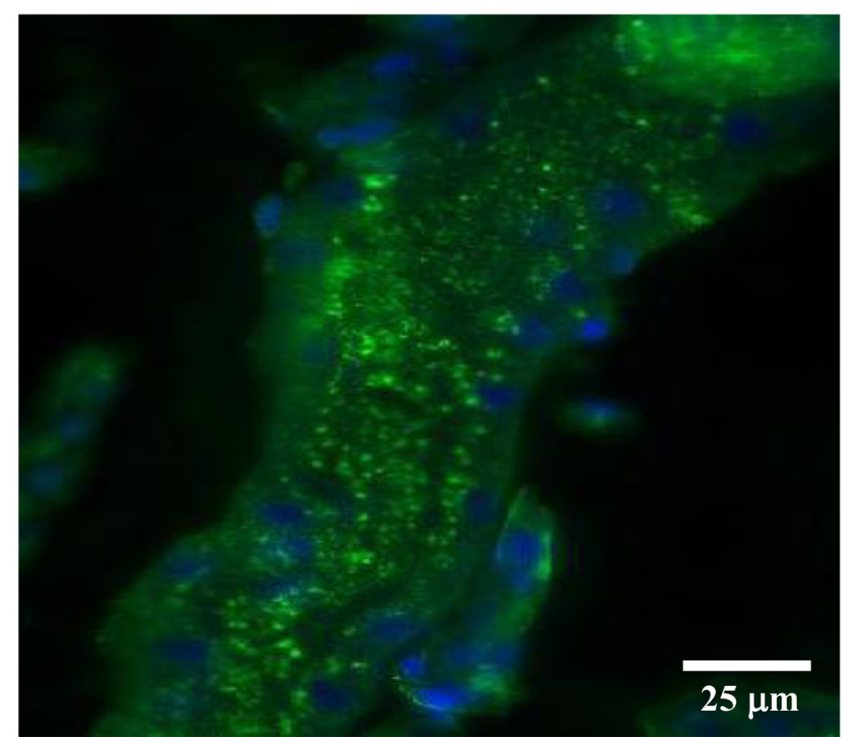

Fig. 4. Immunohistochemical staining for $\mathrm{Gb} 3$ in the proximal renal tubules. The contents of vacuoles are positive for $\mathrm{Gb} 3 \mathrm{immu}-$ nohistochemical staining.

in the ICR mouse was identified as lysosomal accumulation of Gb3.

Spontaneous cytoplasmic vacuolation in renal tubules has been reported in several strains of mice, although the incidence has been reported to be low. In some cases, they were considered to be accumulations of apolipoprotein B and glycoprotein ${ }^{6-13}$. However, spontaneous vacuolation in renal tubules resulting from lysosomal accumulation of glycolipids, including $\mathrm{Gb3}$, has not been reported except in
$\alpha$-Gal A-deficient mice. Therefore, to the best of our knowledge, this is the first report demonstrating spontaneous accumulation of $\mathrm{Gb} 3$ in lysosomes of proximal tubular epithelial cells in normal mice.

In the vehicle-administered mice in our study, excluding the present case, neither vacuolation nor immunohistochemically Gb3-positive findings were observed in renal tubules (data not shown). Additionally, the cytoplasmic vacuolation in this case would be beyond the level of spontaneous findings usually observed in normal mice. Therefore, we did not consider that the lysosomal accumulation of Gb3 in this case might occur under physiological conditions. Fabry disease is an X-linked inherited disease caused by a mutation in $\alpha-\mathrm{Gal} \mathrm{A}$, which is responsible for catalyzing glycosphingolipids such as $\mathrm{Gb}^{17,18}$. Fabry disease is classified into 2 categories, the typical and atypical types, depending on $\alpha$-Gal A activity ${ }^{15}$. Lysosomal accumulation of Gb3 is observed in various organs in the typical type, in which $\alpha$-Gal A activity is completely inactivated, whereas it is observed only in the heart or kidney in the atypical type, in which $\alpha$-Gal A activity is partly reduced ${ }^{19}$. In $\alpha$-Gal Adeficient mice, accumulation of Gb3 is observed in various organs, such as the kidney, liver, spleen, heart and skin ${ }^{20,21}$. As for the present case, spontaneous cytoplasmic vacuolation due to the accumulation of Gb3 was observed only in proximal tubular epithelial cells; therefore, histopathological changes might be caused by the reduction of $\alpha-G a l$ A activity.

In conclusion, this single case of spontaneous cytoplasmic vacuolation in proximal renal tubules in an ICR mouse was confirmed to be lysosomal accumulation of Gb3. 


\section{References}

1. Frazier KS, Seely JC, Hard GC, Betton G, Burnett R, Nakatsuji S, Nishikawa A, Durchfeld-Meyer B, and Bube A. Proliferative and nonproliferative lesions of the rat and mouse urinary system. Toxicol Pathol. 40: 14S-86S. 2012. [Medline]

2. Whiting PH, Petersen J, and Simpson JG. Gentamicin-induced nephrotoxicity in mice: protection by loop diuretics. Br J Exp Pathol. 62: 200-206. 1981. [Medline]

3. Asaoka Y, Togashi Y, Imura N, Sai T, Miyoshi T, and Miyamoto Y. Immunohistochemistry of LAMP-2 and adipophilin for phospholipidosis in liver and kidney in ketoconazole-treated mice. Exp Toxicol Pathol. 65: 817-823. 2013. [Medline]

4. Morishima H, Nonoyama T, Sasaki S, and Miyajima H. Spontaneous lesions in beagle dogs used in toxicity studies. Jikken Dobutsu. 39: 239-248. 1990. [Medline]

5. Ito T, Chatani F, Sasaki S, Ando T, and Miyajima H. Spontaneous lesions in cynomolgus monkeys used in toxicity studies. Jikken Dobutsu. 41: 455-469. 1992. [Medline]

6. Johnson RC, Dovey-Hartman BJ, Syd J, Leach MW, Frank DW, Sinha DP, Mirro EJ, Little JM, and Halliwell WH. Vacuolation in renal tubular epithelium of Cd-1 mice: an incidental finding. Toxicol Pathol. 26: 789-792. 1998. [Medline]

7. Yabuki A, Suzuki S, Matsumoto M, and Nishinakagawa H. Sexual dimorphism of proximal straight tubular cells in mouse kidney. Anat Rec. 255: 316-323. 1999. [Medline]

8. Yabuki A, Suzuki S, Matsumoto M, and Nishinakagawa H. Sex- and strain-dependent histological features of the proximal convoluted tubular epithelium of mouse kidney: association with lysosomes containing apolipoprotein B. Histol Histopathol. 17: 1-7. 2002. [Medline]

9. Yabuki A, Matsumoto M, Nishinakagawa H, and Suzuki S. Giant lysosomes in the renal proximal tubules--a morphological characteristic of DBA/2 and DBA/1 mouse kidneys. Exp Anim. 52: 159-163. 2003. [Medline]

10. Yabuki A, Suzuki S, Matsumoto M, and Nishinakagawa H. Effects of sex hormones on the development of giant lysosomes in the proximal tubules of DBA/2Cr mouse kidney. $\mathrm{J}$ Anat. 202: 445-452. 2003. [Medline]

11. Yabuki A, Suzuki S, Matsumoto M, and Nishinakagawa H. Sex and strain differences in the brush border and PASpositive granules and giant bodies of the mouse renal S3 segment cells. Exp Anim. 50: 59-66. 2001. [Medline]

12. Yabuki A, Suzuki S, Matsumoto M, Kurohmaru M, Hayashi $\mathrm{Y}$, and Nishinakagawa $\mathrm{H}$. Staining pattern of the brush border and detection of cytoplasmic granules in the uriniferous tubules of female DBA/2Cr mouse kidney: comparison among various fixations and stains. J Vet Med Sci. 63: 1339-1342. 2001. [Medline]

13. Yabuki A, Suzuki S, Matsumoto M, and Nishinakagawa H. Lectin-histochemical and -cytochemical study of periodic acid Schiff-Positive lysosomes granules as a histological feature of the female mouse kidney. Histol Histopathol. 17: 1017-1024. 2002. [Medline]

14. Kolling GL, Obata F, Gross LK, and Obrig TG. Immunohistologic techniques for detecting the glycolipid $\mathrm{Gb} 3$ in the mouse kidney and nervous system. Histochem Cell Biol. 130: 157-164. 2008. [Medline]

15. Ohshima T, Murray GJ, Swaim WD, Longenecker G, Quirk JM, Cardarelli CO, Sugimoto Y, Pastan I, Gottesman MM, Brady RO, and Kulkarni AB. Alpha-Galactosidase A deficient mice: a model of Fabry disease. Proc Natl Acad Sci USA. 94: 2540-2544. 1997. [Medline]

16. Valbuena C, Oliveira JP, Carneiro F, Relvas S, Ganhão M, Sá-Miranda MC, and Rodrigues LG. Kidney histologic alterations in $\alpha$-Galactosidase-deficient mice. Virchows Arch. 458: 477-486. 2011. [Medline]

17. Schiffmann R. Fabry disease. Pharmacol Ther. 122: 65-77. 2009. [Medline]

18. Mather AR, and Siskind LJ. Glycosphingolipids and kidney disease. Adv Exp Med Biol. 721: 121-138. 2011. [Medline]

19. Ko YH, Kim HJ, Roh YS, Park CK, Kwon CK, and Park MH. Atypical Fabry's disease. An oligosymptomatic variant. Arch Pathol Lab Med. 120: 86-89. 1996. [Medline]

20. Ohshima T, Schiffmann R, Murray GJ, Kopp J, Quirk JM, Stahl S, Chan CC, Zerfas P, Tao-Cheng JH, Ward JM, Brady RO, and Kulkarni AB. Aging accentuates and bone marrow transplantation ameliorates metabolic defects in Fabry disease mice. Proc Natl Acad Sci USA. 96: 6423-6427. 1999. [Medline]

21. Aerts JM, Groener JE, Kuiper S, Donker-Koopman WE, Strijland A, Ottenhoff R, van Roomen C, Mirzaian M, Wijburg FA, Linthorst GE, Vedder AC, Rombach SM, CoxBrinkman J, Somerharju P, Boot RG, Hollak CE, Brady $\mathrm{RO}$, and Poorthuis BJ. Elevated globotriaosylsphingosine is a hallmark of Fabry disease. Proc Natl Acad Sci USA. 105: 2812-2817. 2008. [Medline] 